\title{
FOS-like antigen 1 is highly expressed in human psoriasis tissues and promotes the growth of HaCaT cells in vitro
}

\author{
WU ZHU ${ }^{1}$, JING LI ${ }^{2}$, JUAN SU ${ }^{1}$, JIE LI ${ }^{1}$, JINMAO LI ${ }^{1}$, BO DENG ${ }^{1}$, \\ QIAN SHI ${ }^{1}$, YANHONG ZHOU ${ }^{3}$ and XIANG CHEN ${ }^{1}$ \\ Departments of ${ }^{1}$ Dermatology and ${ }^{2}$ Neurology, Xiangya Hospital, Central South University, Changsha, Hunan 410008; \\ ${ }^{3}$ Molecular Genetics Laboratory, Cancer Research Institute, Central South University, Changsha, Hunan 410078, P.R. China
}

Received December 20, 2013; Accepted June 26, 2014

DOI: $10.3892 / \mathrm{mmr} .2014 .2509$

\begin{abstract}
Psoriasis is a multifactorial disease and the mechanisms involved in its pathogenesis remain to be elucidated. FOS-like antigen 1 (Fra-1) is a proto-oncogene. It is a negative inhibitor of activator protein-1 activity and possesses transforming activity. The effect of and possible mechanisms underlying Fra-1 in psoriasis remain to be elucidated. In the present study, western blot analysis and reverse transcription-quantitative polymerase chain reaction (RT-qPCR) techniques were used to identify differentially expressed Fra-1 in psoriatic and in normal control tissues. Compared with the control samples, the expression of normalized Fra-1 genes in psoriasis was 12.6 times higher. Western blot analysis was used to assess the protein levels of Fra-1. The results demonstrated that the protein expression of Fra-1 was high in tissues affected by psoriasis. This also corresponded with the results of RT-qPCR. Fra-1-stable expressing HaCaT/Fra-1 or control $\mathrm{HaCaT} /$ vector cell lines were then generated to elucidate the function of Fra-1 in the growth of $\mathrm{HaCaT}$ cells. The results demonstrated that Fra-1 promoted the growth of HaCaT cells in vitro by arresting the cell cycle and inhibiting cell apoptosis. These results suggested that Fra-1 may be important in psoriasis.
\end{abstract}

Correspondence to: Professor Xiang Chen, Department of Dermatology, Xiangya Hospital, Central South University, 87 Xiangya Road, Changsha, Hunan 410008, P.R. China

E-mail: chenxiangck@gmail.com

Dr Yanhong Zhou, Molecular Genetics Laboratory, Cancer Research Institute, Central South University, 110 Xiangya Road, Changsha, Hunan 410078, P.R. China

E-mail: zhouyanhong@csu.edu.cn

Abbreviations: Fra-1, FOS-like antigen 1; AP-1, activator protein-1; GAPDH, glyceraldehyde-3-phosphate dehydrogenase

Key words: psoriasis, FOS-like antigen 1, expression, proliferation

\section{Introduction}

Psoriasis is a common chronic and complex autoimmune inflammatory skin disorder, which requires long-term therapy. Genetic background, environmental factors and immune system disturbances with a strong cytokine component, determine the disease epidemiology and clinical spectrum, which are heterogeneous in different populations. However, the mechanisms involved in the pathogenesis of psoriasis remain to be elucidated (1-4).

FOS-like antigen 1 (Fra-1) is a proto-oncogene, located on chromosome 11q13, encoding a length of $1.7 \mathrm{~kb}$ mature mRNA. Fra-1 was initially characterized as an immediate early transcriptional response gene that is antigenically associated with c-Fos and induced by serum $(5,6)$. While the basic-leucine zipper domain of Fra-1 is homologous to that of other Fos family members, previous initial transcriptional activation studies suggested that Fra-1 is a negative inhibitor of activator protein-1 (AP-1) activity $(7,8)$. Subsequently, Bergers et al demonstrated that Fra-1 had transforming activity (9). Investigations into the molecular mechanisms responsible for skin inflammation have revealed that Jun proteins control cytokine expression, including granulocyte colony-stimulating factor, interleukin- 6 and tumor necrosis factor- $\alpha$ by transcriptional and post-transcriptional pathways $(10,11)$. However, the effect of Fra-1 in psoriasis and its possible underlying mechanisms remain to be elucidated (12-18).

A disturbance during cell division can lead to abnormal cell proliferation and dysregulation in molecular signaling is commonly associated with altered cell growth, cell cycle progression and impaired apoptotic responses in diseases (19-21). Apoptosis is the selective process of physiological cell deletion that regulates the balance between cell proliferation and cell death. The failure of apoptosis is considered to contribute to the development of certain human diseases, such as psoriasis, non-alcoholic fatty liver disease and acute myelogenous leukemia $(22,23)$.

In the present study, the reverse transcription-quantitative polymerase chain reaction (RT-qPCR) technique was used to identify differentially expressed Fra-1 in psoriatic and in normal control tissues. Western blot analysis and flow cytometry were then used to assess the protein levels of Fra-1. Finally, Fra-1-stable expressing $\mathrm{HaCaT} / \mathrm{Fra}-1$ or control $\mathrm{HaCaT} /$ vector 
cell lines were constructed in order to elucidate the function of Fra-1 in the growth of HaCaT cells.

\section{Materials and methods}

Cell culture. The HaCaT cells were cultured in complete culture medium composed of Dulbecco's modified Eagle's medium (DMEM; Gibco-BRL, Grand Island, NY, USA), 10\% fetal bovine serum (Gibco BRL), $100 \mathrm{U} / \mathrm{ml}$ penicillin and $100 \mathrm{U} / \mathrm{ml}$ streptomycin (both Hyclone Laboratories, South Logan, UT, USA). The cells were maintained in a humidified atmosphere of $95 \%$ air and $5 \% \mathrm{CO}_{2}$ at $37^{\circ} \mathrm{C}$.

Patient samples. Tissue samples from 10 psoriatic tissues and 10 normal control tissues were obtained from Xiangya Hospital, Central South University (Changsha, China). The patients were informed about the sample collection and written informed consent was obtained from each patient. The collection and use of tissues samples was approved by the ethical review committees of Xiangya Hospital. At the Xiangya Hospital, 10 cases of psoriasis were confirmed histologically and 10 normal control tissue samples were collected from individual patients with traumatism. All subjects enrolled in the study were of the Chinese Han population and all clinical and biological data were available for the samples (Table I). No significant differences in gender or age were identified between the psoriatic and control groups $(\mathrm{P}>0.05)$. Samples were separated from the surgical patient tissue samples, immediately snap-frozen in liquid nitrogen (Zhen Kuuan Inc., Shenzhen, China) and stored until use.

RNA extraction and RT-qPCR analysis. Total RNA was extracted from the biopsy samples using an RNeasy ${ }^{\circledR}$ kit (Qiagen, Carlsbad, CA, USA) according to the manufacturer's instructions. The total RNA samples $(1 \mu \mathrm{g})$ were used to generate cDNA. Following the reverse transcription reaction, the PCR reaction was preceded. All RT-qPCR reactions were repeated at least three times at different points of the extension cycle to avoid false results from the PCR. GAPDH was used as an endogenous control for normalization. The primer sequences used for RT-qPCR were as follows: Fra-1, forward 5'-cgaaggcettgtgaacagat-3' and reverse 5'-cttctgcttctgcagctcct-3'; GAPDH, forward 5'-cgaccactttgtcaagctca-3' and reverse 5'-actgagtgtggcagggactc-3'. The expression of mRNA was assessed using evaluated threshold cycle (CT) values. The CT values were normalized with the expression levels of GAPDH and the relative quantity of mRNA specific to each of the target genes was calculated using the $2^{-\Delta \Delta C \mathrm{CT}}$ method (24-26).

Western blot analysis. The proteins of the biopsy samples were prepared using a lysis buffer (RIPA buffer; CWBio, Beijing, China) and the protein concentrations were determined using the bicinchoninic acid protein assay (Pierce Biotechnology, Inc., Rockford, IL, USA). Extracts containing $50 \mu \mathrm{g}$ protein were separated on 10\% SDS-PAGE gels and electroblotted onto nitrocellulose membranes (HyClone Laboratories Inc.). The membranes were inhibited using Tris-buffered saline/Tween 20 (25 mM Tris-hydrochloride, $150 \mathrm{mM}$ sodium chloride, $\mathrm{pH} 7.5$ and $0.05 \%$ Tween 20) containing $5 \%$ non-fat milk. This was followed by overnight
Table I. Characteristics of cases of psoriasis and controls

\begin{tabular}{llcl}
\hline Sample & Gender & Age (years) & \multicolumn{1}{c}{ Diagnosis } \\
\hline 1 & Male & 43 & Psoriasis \\
2 & Male & 57 & Psoriasis \\
3 & Female & 43 & Psoriasis \\
4 & Male & 43 & Psoriasis \\
5 & Male & 29 & Psoriasis \\
6 & Male & 43 & Psoriasis \\
7 & Female & 53 & Psoriasis \\
8 & Female & 65 & Psoriasis \\
9 & Male & 70 & Psoriasis \\
10 & Female & 37 & Psoriasis \\
11 & Female & 44 & Normal control tissue \\
12 & Female & 42 & Normal control tissue \\
13 & Female & 58 & Normal control tissue \\
14 & Male & 41 & Normal control tissue \\
15 & Female & 30 & Normal control tissue \\
16 & Female & 43 & Normal control tissue \\
17 & Male & 55 & Normal control tissue \\
18 & Male & 67 & Normal control tissue \\
19 & Male & 71 & Normal control tissue \\
20 & Female & 35 & Normal control tissue \\
\hline & & &
\end{tabular}

incubation at $4^{\circ} \mathrm{C}$ with primary antibodies (1:500 polyclonal rabbit anti-Fra-1 antibody; Santa Cruz Biotechnology, Inc., Santa Cruz, CA, USA). Following washing three times, secondary antibodies $(1: 2,000$ horseradish peroxidaseconjugated monoclonal mouse anti-rabbit antibodies; Santa Cruz Biotechnology Inc.) were added and incubated for $1 \mathrm{~h}$. Anti- $\beta$-actin antibody (1:3,000; Santa Cruz Biotechnology, Inc.) was used as a loading control.

Cell transfection. To establish a stable Fra-1-expressing cell line, a plasmid (pEGFP-N1/Fra-1) was constructed by inserting the full-length sequence of human Fra-1 cDNA upstream of enhanced green fluorescent protein (EGFP) in the plasmid pEGFP-N1. Subsequently, the plasmid pEGFP-N1/Fra-1 or empty control vector pEGFP-N1 were transfected into $\mathrm{HaCaT}$ cells, respectively, using Lipofectin (Invitrogen Life Technologies, Carlsbad, CA, USA) according to the manufacturer's instructions, followed by G418 selection. The stable transfectants, $\mathrm{HaCaT} / \mathrm{Fra}-1$ and $\mathrm{HaCaT} /$ vector, were isolated and the transcription of Fra-1 mRNA was determined using RT-qPCR with specific primers (forward 5'-cgaaggcettgtgaacagat-3' and reverse 5'-cttctgcttctgcagctcct-3').

Cell proliferation assay. The impact of Fra- 1 on $\mathrm{HaCaT}$ cell proliferation was measured using an MTT assay, as described previously (14). Briefly, the $\mathrm{HaCaT}, \mathrm{HaCaT} /$ vector and $\mathrm{HaCaT} /$ Fra-1 cells $\left(10^{4}\right.$ cells/well) were cultured in triplicate with $10 \%$ fetal calf serum (FCS) DMEM in 96-well plates. The cells were then exposed to $5 \mathrm{mg} / \mathrm{ml}$ MTT for $4 \mathrm{~h}$. The generated formazan was dissolved with dimethyl sulfoxide and measured at $570 \mathrm{~nm}$ using an ELX-800 microplate reader (Bio-Tek Instruments, Inc., Winooski, VT, USA). 
Table II. Identification of mRNA expression level of the Fra-1 gene in psoriasis by RT-qPCR.

\begin{tabular}{|c|c|c|c|c|c|c|c|}
\hline Gene & Sample & $\mathrm{N}$ & $\begin{array}{l}\mathrm{GAPDH} \mathrm{C}_{\mathrm{T}} \\
(\text { mean } \pm \mathrm{SD})\end{array}$ & $\begin{array}{c}\text { Fra-1 } \mathrm{C}_{\mathrm{T}} \\
(\text { mean } \pm \mathrm{SD})\end{array}$ & $\begin{array}{c}\Delta \mathrm{C}_{\mathrm{T}} \\
(\text { mean } \pm \mathrm{SD})\end{array}$ & $\begin{array}{c}\Delta \Delta \mathrm{C}_{\mathrm{T}} \\
(\text { mean } \pm \mathrm{SD})\end{array}$ & Fold \\
\hline \multirow[t]{2}{*}{ Fra-1 } & Psoriasis & 10 & $17.41 \pm 1.51$ & $29.32 \pm 1.41$ & $11.91 \pm 0.91$ & $-3.66 \pm 0.74$ & 12.60 \\
\hline & Control & 10 & $18.23 \pm 1.75$ & $33.79 \pm 1.63$ & $15.56 \pm 1.12$ & & \\
\hline
\end{tabular}

RT-qPCR products from 10 psoriasis and 10 control tissues. The mean fold change in expression of the target gene was calculated using Eq., where $\Delta \Delta \mathrm{CT}=\left(\mathrm{CT}_{\text {Target }}-\mathrm{CT}_{\mathrm{GAPDH}}\right)_{\text {psoriasis }}-\left(\mathrm{CT}_{\text {Target }}-\mathrm{CT}_{\mathrm{GAPDH}}\right)_{\text {control }}$. At least three replicates of each reaction were performed. The fold change in expression of the target gene (Fra-1) relative to the internal control gene (GAPDH) was determined using the $2^{-\Delta \Delta C T}$ method. SD, standard deviation; Fra-1, fos-like antigen 1; RT-qPCR, reverse transcription-quantitative polymerase chain reaction.

Flow cytometric analysis of the cell cycle. The HaCaT, $\mathrm{HaCaT} /$ vector and $\mathrm{HaCaT} / \mathrm{Fra}-1$ cells were cultured in $10 \%$ FCS DMEM up to $\sim 70 \%$ confluence. The adherent cells were trypsinized, harvested and fixed in $70 \%$ ethanol (Huihong Inc., Changsha, China) at $4^{\circ} \mathrm{C}$. Subsequently, the cells were washed with cold phosphate-buffered saline (PBS; Solarbio Inc., Beijing, China) and stained with propidium iodide (PI; Biotium Inc, Hayward, CA, USA) in working solution $(0.5 \mathrm{mg} / \mathrm{ml}$ RNase and $0.1 \mathrm{mg} / \mathrm{ml}$ PI in PBS). The cell cycle was characterized by flow cytometric analysis using a MoFlo $^{\text {TM }}$ XDP High-Performance Cell Sorter (Beckman Coulter, Miami, FL, USA) and the data were analyzed by the CellQuest software version 3.0 (Becton Dickinson, San Jose, CA, USA).

Effect of Fra-1 on HaCaT cell apoptosis. Cell apoptosis was analyzed by flow cytometric analysis using a MoFlo ${ }^{\mathrm{TM}}$ XDP High-Performance Cell Sorter (Beckman Coulter) and PI + annexin V-fluorescein isothiocyanate (FITC) double staining (Nanjing KeyGen Biotech Co., Ltd., Nanjing, China). Briefly, the HaCaT, HaCaT/Fra-1 and $\mathrm{HaCaT} /$ vector cells were seeded at a density of $3 \times 10^{5}$ cells per well in 24 -well culture plates. Cells were collected in an Eppendorf tube at $24 \mathrm{~h}$ and washed twice with PBS by centrifugation at $500 \mathrm{x} \mathrm{g}$ for $10 \mathrm{~min}$. The supernatants were discarded. To detect apoptosis, $500 \mu \mathrm{l}$ PBS, $5 \mu \mathrm{l}$ Annexin V-FITC and $5 \mu \mathrm{l}$ PI were added to each tube and the contents of the tube were mixed in the dark at room temperature for $15 \mathrm{~min}$, followed by flow cytometric analysis. Data were acquired and analyzed with Summit v5.2 software (Becton-Dickinson, Franklin Lakes, NJ, USA).

Statistical analysis. Differences between nonparametric variables were analyzed by Fisher's exact test using EPI software (EPI Info, version 3.2.2, www.cdc.gov/epiinfo). Differences in the quantitative variables between groups were analyzed by Student's t-test using SPSS 11.0 program (SPSS, Inc., Chicago, IL, USA). $\mathrm{P}<0.05$ was considered to indicate a statistically significant difference.

\section{Results}

Detection of mRNA expression levels of the Fra-1 gene in psoriasis. To detect the mRNA expression levels of the Fra-1 gene in psoriasis and in controls, 10 psoriatic and 10 control tissue samples were obtained to perform RT-qPCR on the Fra-1 genes. Sample spreadsheet of data analysis using the $2^{-\Delta \Delta \mathrm{CT}}$ method. The fold change in the expression of the Fra-1 gene relative to the internal control gene (GAPDH) was investigated. Expression of the Fra-1 gene was high in psoriasis (Table II; Fig. 1) and, compared with the control samples, the normalized gene expression of Fra-1 in psoriasis was 12.6 times higher (Fig. 1C). Fig. 1A and B show the results of the agarose gel electrophoresis following RT-qPCR for the Fra-1 and GAPDH genes in psoriasis and in the control. Fra-1 was highly expressed in 10 psoriasis samples compared with the control samples (Fig. 1A and B). In two of the 10 control samples, the expression of Fra-1 gene was not deleted (Fig. 1B).

Analysis of protein expression levels of the Fra-1 gene in psoriasis by western blot analysis. To determine whether Fra-1 had a higher level of expression in psoriasis than in the control, the levels of Fra-1 protein expression were examined in psoriasis and in controls using western blot analysis. In comparison with the control, the protein expression of Fra-1 was highly expressed in psoriatic compared with the control tissues (Fig. 2), particularly in the specimen 5, 7 and 9. This corresponded with the results of RT-qPCR and again confirmed that Fra-1 was highly expressed in psoriatic tissues.

Fra-1 promotes the growth of HaCaT cells in vitro. In order to elucidate the function of Fra-1 in the growth of $\mathrm{HaCaT}$ cells, the HaCaT cells were transfected with either the plasmid pEGFP-N1/Fra-1 or a control vector to generate Fra-1-stable expressing HaCaT/Fra-1 or control HaCaT/vector cell lines. Following demonstrating Fra-1 mRNA transcription by RT-qPCR, the spontaneous proliferation of $\mathrm{HaCaT}$, $\mathrm{HaCaT} /$ vector and $\mathrm{HaCaT} / \mathrm{Fra}-1$ cells was determined using MTT assays. Notably, Fra-1 significantly promoted the proliferation of HaCaT cells (Fig. 3). Therefore, endogenous Fra-1 overexpression promoted the proliferation of $\mathrm{HaCaT}$ cells in vitro.

Fra-1 induces HaCaT cell cycle arrest and inhibits cell apoptosis. The promotion of cell proliferation is usually mediated by inducing cell cycle arrest and/or inhibiting cell apoptosis. To assess this possibility, the cell cycle of HaCaT, the $\mathrm{HaCaT} /$ vector and $\mathrm{HaCaT} / \mathrm{Fra}-1$ cells was examined using FACS analysis. Compared with the $\mathrm{HaCaT}$ and $\mathrm{HaCaT} /$ vector cells, the percentage of HaCaT/Fra-1 cells that remained at the $\mathrm{S}$ phase of the cell cycle was increased $(27.9,28.9$ and $35.6 \%$, respectively), accompanied by a reduction in the percentage of the cells in the G0/G1-phase $(61.2,60.5$ and $51.4 \%$, 
A
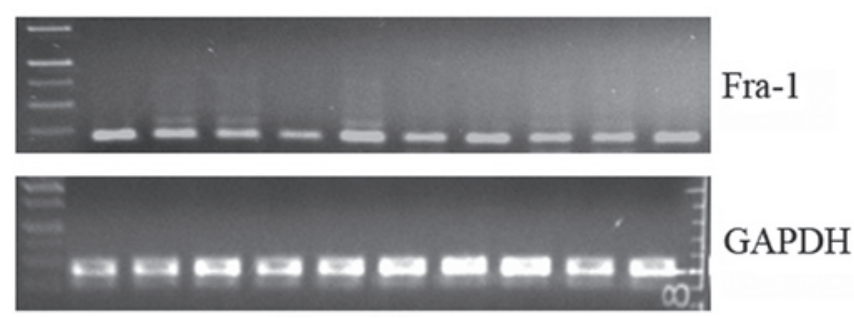

B

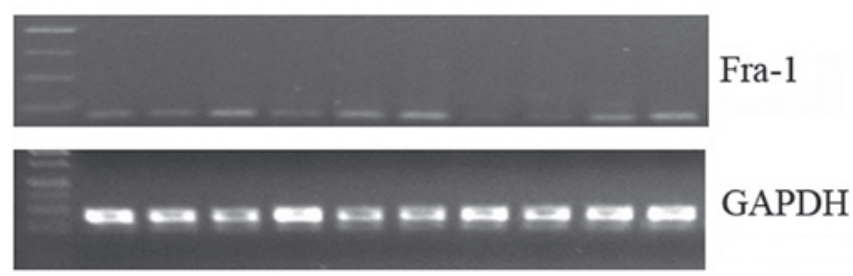

C

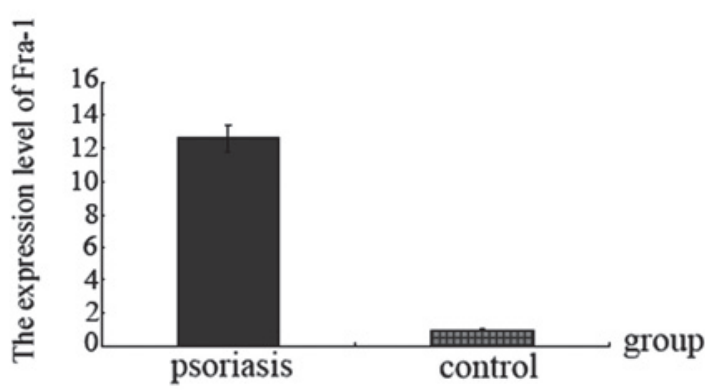

Figure 1. Differential expression of the Fra-1 gene in psoriasis and in the control. (A and B) Results of agarose gel electrophoresis of reverse transcription-quantitative polymerase chain reaction for Fra-1 and GAPDH genes in psoriasis and in the control. (C) Normalized Fra-1 gene expression was 12.6 times higher in psoriatic samples than in control samples. Fra-1, Fos-like antigen 1.

A

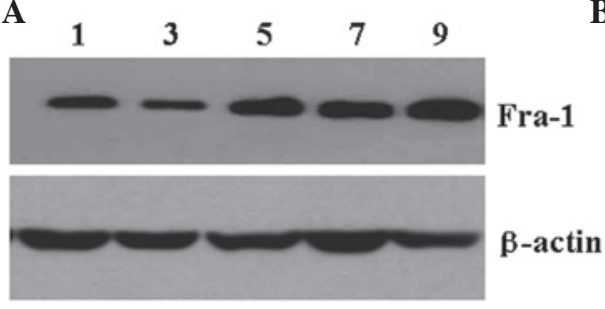

B

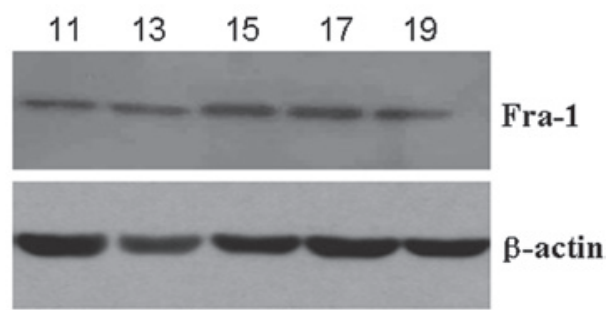

Figure 2. Levels of Fra-1 protein expression in psoriasis and in the control. Five psoriasis tissues and five control tissues were selected to detect the expression levels of the Fra-1 protein by western blot analysis. (A) Five psoriatic tissue samples, (B) five control tissue samples. Data shown are one representative of three independent experiments. Fra-1, Fos-like antigen 1.

respectively; Table III). To determine whether apoptosis mediated cell growth in $\mathrm{HaCaT}, \mathrm{HaCaT} /$ vector and $\mathrm{HaCaT} / \mathrm{Fra}-1$ cells, an annexin V-FITC/PI double-staining experiment was performed. As shown in Fig. 4, a considerable decrease in the percentage of apoptotic cells was observed in HaCaT/Fra-1 cells $(2.36 \pm 0.42 \%)$ compared with $\mathrm{HaCaT}$ cells $(11.07 \pm 0.82 \%)$ and $\mathrm{HaCaT} /$ vector cells $(10.83 \pm 0.79 \%)$.

\section{Discussion}

Psoriasis is a cutaneous and articular disease, the incidence of which ranges between 1 and $3 \%$. It is a chronic recurrent inflammatory skin disorder with a multifactorial etiology, including genetic background, environmental factors and immune system disturbances with a strong cytokine component (1-4). A study by Gunduz et al demonstrated that there are similar expression levels of NF- $\mathrm{NB}$ and survivin in normal and psoriatic epidermis, and that survivin and NF- $\kappa \mathrm{B}$ levels cannot be attributed to the epidermal proliferation and thickness observed in psoriasis (27). A study by Han et al supported observations that apolipoprotein E polymorphisms are associated with the risk of psoriasis, particularly the $\varepsilon 2$ and $\varepsilon 3$ alleles (28). However, the effect and possible mechanisms of Fra-1 in psoriasis remain to be elucidated.

In order to identify the levels of Fra-1 mRNA expression in psoriasis, the RT-qPCR technique was used for analysis. Compared with the control samples, the normalized Fra-1 gene expression in psoriasis was 12.6 times higher. Western 
Table III. Cell cycle analysis of the HaCaT, HaCaT/vector and HaCaT/Fra-1 cells by flow cytometry.

\begin{tabular}{lccc}
\hline & \multicolumn{3}{c}{ Phase of cell cycle $^{\mathrm{a}}$} \\
\cline { 2 - 4 } Cell line & $\% \mathrm{G}_{0}-\mathrm{G}_{1}$ & $\% \mathrm{~S}$ & $\% \mathrm{G}_{2}-\mathrm{M}$ \\
\hline $\mathrm{HaCaT}$ & $61.2 \pm 5.4$ & $27.9 \pm 2.9$ & $10.9 \pm 0.9$ \\
$\mathrm{HaCaT} /$ vector & $60.5 \pm 5.1$ & $28.9 \pm 3.1$ & $10.6 \pm 0.8$ \\
$\mathrm{HaCaT} /$ Fra-1 & $51.4 \pm 4.6$ & $35.6 \pm 3.5$ & $13.0 \pm 1.1$ \\
\hline
\end{tabular}

${ }^{a}$ Numbers indicate the percentage of cells in the different phases of the cell cycle.

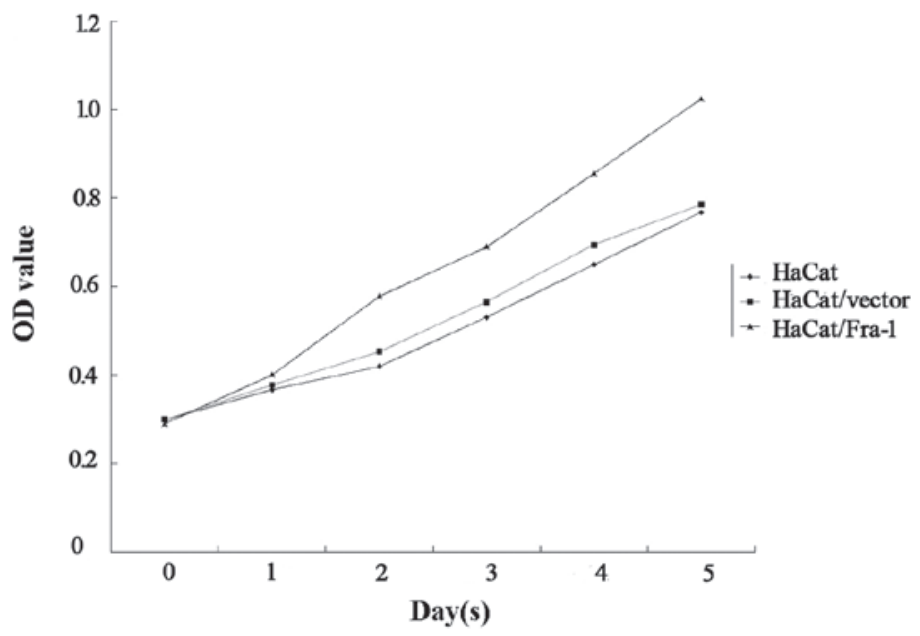

Figure 3. Cell viability of $\mathrm{HaCaT}, \mathrm{HaCaT} /$ vector and $\mathrm{HaCaT} / \mathrm{Fra}-1$ cells using an MTT assay. Endogenous Fra-1 overexpression promoted the proliferation of HaCaT cells in vitro. OD, optical density; Fra-1, Fos-like antigen 1.

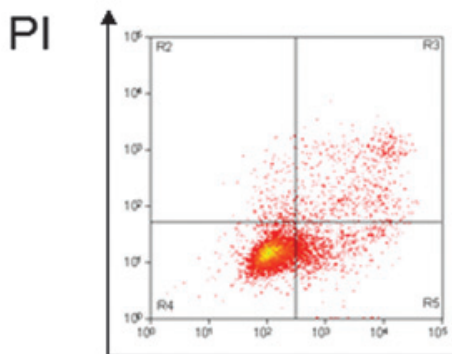

$\mathrm{HaCaT}$

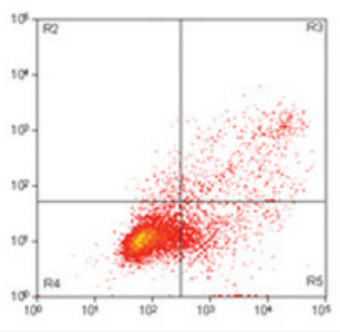

$\mathrm{HaCaT} /$ vector

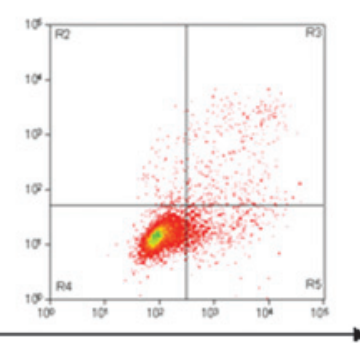

HaCaT/Fra-1

Figure 4. Analysis of cell apoptosis in HaCaT, HaCaT/vector and HaCaT/Fra-1 cells. Double staining with annexin V-fluorescein isothiocyanate and PI demonstrated an decrease in the percentage of apoptotic cells (early and late) in HaCaT/Fra-1 cells compared with HaCaT and HaCaT/vector cells. PI, propidium iodide; Fra-1, Fos-like antigen 1.

blot analysis and flow cytometry were then used to assess the protein levels of Fra-1. The results of the western blotting demonstrated that the level of Fra-1 protein expression was high in the psoriatic tissue samples. This corresponded with the results of the RT-qPCR. The mRNA and protein levels observed in the present study confirmed that the level of Fra-1 expression was high in psoriasis. A previous study revealed that the Fos-related proteins Fra-1 and Fra-2 were possibly causally involved in inflammatory skin diseases, including psoriasis (12). Our data are consistent with previous observations and suggest that Fra-1 may be important in psoriasis.
Furthermore, the results of the present study demonstrated that Fra-1 promotes the growth of $\mathrm{HaCaT}$ cells in vitro by arresting the cell cycle and inhibiting cell apoptosis. Mitogen-activated protein kinase cascades were activated by a variety of environmental stresses, such as hormones and growth factors. In addition, they promoted Jun/AP1 activity and regulated cell proliferation, differentiation, transformation and/or apoptosis. During development and in skin cancer, Jun is known to be a regulator of keratinocyte proliferation and differentiation by its direct transcriptional effect on epidermal growth factor receptor expression (13). 
Johansen et al revealed that the protein and mRNA expression of the AP-1 subunits c-Fos, Fra-1 and c-Jun were reduced in lesional psoriatic skin compared with non-lesional psoriatic skin (14). In this study, we found that Fra-1 was highly expressed in psoriasis tissues and may be important in psoriasis. Thus the effect of Fra-1 on growth, the cell cycle and apoptosis of HaCaT cells was investigated in vitro. The results showed that Fra- 1 could inhibit apoptosis of $\mathrm{HaCaT}$ cells and promote cell growth. Our results offer novel evidence of the association between Fra-1 and psoriasis. However, the detailed mechanism underlying the effect of Fra-1 in psoriasis requires further investigation.

\section{Acknowledgements}

This study was supported by the National Natural Sciences Foundation of China (no. 81272975), the Planned Science and Technology Project of Hunan Province (nos. 2013FJ6004 and 2012TT2002), the Key Project of Hunan Provincial Natural Science Foundation (no. 12JJ2044) and the Planned Project of Department of Health of Hunan Province (no. B-2009-002).

\section{References}

1. Lee YS, Cheon IS, Kim BH, Kwon MJ, Lee HW and Kim TY: Loss of extracellular superoxide dismutase induces severe IL-23-mediated skin inflammation in mice. J Invest Dermatol 133: 732-741, 2013.

2. Grayson M: Psoriasis. Nature 492: S49, 2012.

3. Balato N, Megna M, Di Costanzo L, Balato A and Ayala F: Educational and motivational support service: a pilot study for mobile-phone-based interventions in patients with psoriasis Br J Dermatol 168: 201-205, 2013.

4. Hirotsu C, Rydlewski M, Araújo MS, Tufik S and Andersen ML: Sleep loss and cytokines levels in an experimental model of psoriasis. PLoS One 7: e51183, 2012.

5. Young MR and Colburn NH: Fra-1 a target for cancer prevention or intervention. Gene 379: 1-11, 2006.

6. Rauscher FJ III, Cohen DR, Curran T, Bos TJ, Vogt PK, Bohmann D, Tjian R and Franza BR Jr: Fos-associated protein p39 is the product of the jun proto-oncogene. Science 240: 1010-1016, 1988.

7. Suzuki T, Okuno H, Yoshida T, Endo T, Nishina H and Iba H: Difference in transcriptional regulatory function between c-Fos and Fra-2. Nucleic Acids Res 19: 5537-5542, 1991.

8. Yoshioka K, Deng T, Cavigelli M and Karin M: Antitumor promotion by phenolic antioxidants: inhibition of AP-1 activity through induction of Fra expression. Proc Natl Acad Sci USA 92: 4972-4976, 1995.

9. Bergers G, Graninger P, Braselmann S, Wrighton C and Busslinger M: Transcriptional activation of the fra-1 gene by AP-1 is mediated by regulatory sequences in the first intron. Mol Cell Biol 15: 3748-3758, 1995.

10. Schonthaler HB, Guinea-Viniegra $J$ and Wagner EF: Targeting inflammation by modulating the Jun/AP-1 pathway. Ann Rheum Dis 70 (Suppl 1): i109-i112, 2011.
11. Guinea-Viniegra J, Zenz R, Scheuch H, Hnisz D, Holcmann M, Bakiri L, Schonthaler HB, Sibilia M and Wagner EF: TNFalpha shedding and epidermal inflammation are controlled by Jun proteins. Genes Dev 23: 2663-2674, 2009.

12. Wagner EF: Bone development and inflammatory disease is regulated by AP-1 (Fos/Jun). Ann Rheum Dis 69: i86-i88, 2010.

13. Zenz R and Wagner EF: Jun signalling in the epidermis: From developmental defects to psoriasis and skin tumors. Int J Biochem Cell Biol 38: 1043-1049, 2006.

14. Johansen C, Kragballe K, Rasmussen M, Dam TN and Iversen L: Activator protein 1 DNA binding activity is decreased in lesional psoriatic skin compared with nonlesional psoriatic skin. $\mathrm{Br}$ J Dermatol 151: 600-607, 2004.

15. Oberprieler NG and Taskén K: Analysing phosphorylation-based signalling networks by phospho flow cytometry. Cell Signal 23: 14-18, 2011.

16. Zhou Y, Zeng Z, Zhang W, Xiong W, Wu M, Tan Y, Yi W, Xiao L, Li X, Huang C, Cao L, Tang K, Li X, Shen S and Li G: Lactotransferrin: a candidate tumor suppressor, deficient expression in human nasopharyngeal carcinoma and inhibits NPC cell proliferation by modulating the mitogen-activated protein kinase pathway. Int J Cancer 123: 2065-2072, 2008.

17. Krutzik PO, Irish JM, Nolan GP and Perez OD: Analysis of protein phosphorylation and cellular signaling events by flow cytometry: techniques and clinical applications. Clin Immunol 110: 206-221, 2004.

18. Zhang L, Tang A, Zhou Y, Tang J, Luo Z, Jiang C, Li X, Xiang J and Li G: Tumor-conditioned mesenchymal stem cells display hematopoietic differentiation and diminished influx of $\mathrm{Ca}^{2+}$. Stem Cells Dev 21: 1418-1428, 2012.

19. Li FL, Xu R, Zeng QC, Li X, Chen J, Wang YF, Fan B, Geng L and $\mathrm{Li} \mathrm{B}$ : Tanshinone IIA inhibits growth of keratinocytes through cell cycle arrest and apoptosis: underlying treatment mechanism of psoriasis. Evid Based Complement Alternat Med 2012: 927658, 2012.

20. Abou EL-Ela M, Nagui N, Mahgoub D, El-Eishi N, Fawzy M, El-Tawdy A, Abdel Hay R and Rashed L: Expression of cyclin D1 and p16 in psoriasis before and after phototherapy. Clin Exp Dermatol 35: 781-785, 2010.

21. Wittayarat M, Fujiwara A, Chatdarong K, Techakumphu M, Sato Y, Tanihara F, Morita Y, Taniguchi M and Otoi T: Cell cycle analysis and interspecies nuclear transfer of cat cells treated with chemical inhibitors. Acta Vet Hung 62: 233-242, 2014.

22. Mok CF, Xie CM, Sham KW, Lin ZX and Cheng $\mathrm{CH}$ : 1,4-dihydroxy-2-naphthoic acid induces apoptosis in human keratinocyte: potential application for psoriasis treatment. Evid Based Complement Alternat Med 2013: 792840, 2013.

23. Broshtilova V, Lozanov V and Miteva L: Polyamine metabolism changes in psoriasis. Indian J Dermatol 58: 306-309, 2013.

24. Livak KJ and Schmittgen TD: Analysis of relative gene expression data using real-time quantitative PCR and the 2(-Delta Delta C(T)) Method. Methods 25: 402-408, 2001.

25. Zhou Y, Wang W, Zheng D, Peng S, Xiong W, Ma J, Zeng Z, Wu M, Zhou M, Xiang J, Xiang B, Li X, Li X and Li G: Risk of nasopharyngeal carcinoma associated with polymorphic lactotransferrin haplotypes. Med Oncol 29: 1452-1462, 2012.

26. Ruan L, Wang GL, Chen Y, Yi H, Tang CE, Zhang PF, Li MY, Li C, Peng F, Li JL, Chen ZC and Xiao ZQ: Identification of tyrosine phosphoproteins in signaling pathway triggered TGF- $\alpha$ by using functional proteomics technology. Med Oncol 27: 1407-1414, 2010.

27. Gunduz K, Temiz P, Gencoglan G, Inanir I and Catalkaya A: Expression of nuclear factor kappa B and survivin in psoriasis. ISRN Dermatol 2012: 257059, 2012

28. Han Y, Liu T and Lu L: Apolipoprotein E gene polymorphism in psoriasis: a meta-analysis. Arch Med Res 44: 46-53, 2013. 